\title{
QTcB Prolongation
}

National Cancer Institute

\section{Source}

National Cancer Institute. QT CB Prolongation. NCI Thesaurus. Code C107098.

An electrocardiog raphic finding in which the QT interval corrected for heart rate using Bazett's formula is prolonged. Thresholds for different age, gender, and patient populations exist. (CDISC) 